\title{
Coating
}

Chao Zheng, Dongfang Li and Monica Ek*

\section{Improving fire retardancy of cellulosic thermal insulating materials by coating with bio-based fire retardants}

https://doi.org/10.1515/npprj-2018-0031

Received July 22, 2018; accepted November 8, 2018; previously published online February 2, 2019

Abstract: Sustainable thermal insulating materials produced from cellulosic fibers provide a viable alternative to plastic insulation foams. Industrially available, abundant, and inexpensive mechanical pulp fiber and recycled textile fiber provide potential raw materials to produce thermal insulating materials. To improve the fire retardancy of low-density thermal insulating materials produced from recycled cotton denim and mechanical pulp fibers, bio-based fire retardants, such as sulfonated kraft lignin, kraft lignin, and nanoclays, were coated onto sustainable insulating material surfaces to enhance their fire retardancy. Microfibrillated cellulose was used as a biobased binder in the coating formula to disperse and bond the fire-retardant particles to the underlying thermal insulating materials. The flammability of the coated thermal insulating materials was tested using a single-flame source test and cone calorimetry. The results showed that sulfonated kraft lignin-coated cellulosic thermal insulating materials had a better fire retardancy compared with that for kraft lignin with a coating weight of $0.8 \mathrm{~kg} / \mathrm{m}^{2}$. Nanoclay-coated samples had the best fire retardancy and did not ignite under a heat flux of $25 \mathrm{~kW} / \mathrm{m}^{2}$, as shown by cone calorimetry and single-flame source tests, respectively. These cost-efficient and bio-based fire retardants have broad applications for improving fire retardancy of sustainable thermal insulating materials.

Keywords: bio-based; cellulose; coating; fire retardant; thermal insulating material.

\footnotetext{
*Corresponding author: Monica Ek, Department of Fiber and Polymer Technology, KTH Royal Institute of Technology, Teknikringen 56-58, SE-100 44 Stockholm, Sweden, e-mail: monicaek@kth.se Chao Zheng, Dongfang Li, Department of Fiber and Polymer Technology, KTH Royal Institute of Technology, Teknikringen 56-58, SE-100 44 Stockholm, Sweden, e-mails: chaozh@kth.se, dongfan@kth.se, ORCID: https://orcid.org/0000-0002-2272-5067 (C. Zheng)
}

\section{Introduction}

Buildings are the largest consumers of energy all over the world, e. g., $40 \%$ of global energy is used for heating and cooling in buildings (El-Darwish and Gomaa 2017). To improve the energy efficiency of buildings, thermal insulating materials are used to reduce energy consumption.

Bio-based materials produced from renewable resources have recently been developed based on bioeconomy and low-carbon economy concepts. Renewable raw materials, such as pulp fiber and recycled textile fiber, have been used to produce value-added products, such as environmentally friendly thermal insulating materials (Zheng et al. 2017a, Zheng et al. 2017b, Lacoste et al. 2018). These materials are promising alternatives to traditional oil-based thermal insulating products. However, fire safety concerns of low-density thermal insulating materials have yet to be addressed. Generally, the fire retardancy of thermal insulating materials is improved using fire retardants. Conventional halogen-based fire retardants have potential health risks and produce toxic gases when inflamed (Yurddaskal and Celik 2018). As such, alternative bio-based fire retardants have been proposed to address health and environmental concerns. A few bio-based fire retardants, such as lignin and nanoclay, have been shown to have the potential to decrease flammability.

Lignin is an abundant by-product that can be obtained from pulp and paper industries. The aromatic chemical structure in lignin promotes the formation of a high char yield after decomposition (approximately $40 \%$ at $900^{\circ} \mathrm{C}$ ) (Ferry et al. 2015). The char layer can protect the underlying substrate from further decomposition and improve fire retardancy. Therefore, lignin has potential as a fire retardant. While lignin has seldom been studied as a fire retardant in cellulosic thermal insulating materials, several studies have explored applications of lignin as fire retardants in plastic. For example, lignin has been shown to create protective char layers in polypropylene (PP), polyethylene terephthalate (PET), polyhydroxybutyrate (PHB), and acrylonitrile butadiene styrene (ABS) to enhance the fire retardancy of these plastics (Canetti et al. 
2006, Canetti and Bertini 2007, Mousavioun et al. 2010, Song et al. 2011, Bertini et al. 2012). Nanoclays, such as montmorillonite and vermiculite, have been used as fireretardant coatings or fillers in polymers. The ordered distribution of nanosized clay particles can improve the gas barrier property, fire retardancy and mechanical performance (Shan etal. 2015, Chatterjee et al. 2017, Hu et al. 2017).

Fire retardant coatings have become promising treatment options for improving the fire retardancy of materials due to their effective, efficient, and economic advantages. Recent research on the applications of fire retardant coatings has shown that these coatings protect underlying substrate materials from fire damage and enhance their mechanical properties. At present, oil-based binders, such as acrylic resin and epoxy resin, are the most commonly used additives in coating formulation for creating thin films on substrate surfaces. Novel coating materials have been under development as sustainable alternatives in pulp fiberbased packaging material to replace these oil-based coatings. One such material, microfibrillated cellulose (MFC), can improve the strength and stiffness of paper materials. As a coating additive in paper coating formulations, MFC can be used as a co-binder or thickener and thus, serve as a renewable and sustainable alternative to synthetic latex and binders in most coating formulations (Richmond 2014).

In the present study, MFC was used as a binder in coating formulations for different types of fire retardants, namely, sulfonated kraft lignin, kraft lignin, nanoclay, commercial expandable graphite and synergetic fire retardants. These fire retardants dispersed in MFC were coated on the surfaces of cellulosic thermal insulating materials produced from recycled cotton denim fiber and mechanical pulp fiber. The objective of this work was to evaluate and compare the effects of these fire retardant-MFC combinations on fire retardancy and on the thermal and mechanical properties of cellulosic thermal insulating materials.

\section{Materials and methods}

\section{Materials}

Recycled textile fibers with an average length of $1.5 \mathrm{~cm}$ were obtained from the milling of worn-out denim (88.7\% cotton, 9.8\% polyurethane, and $1.5 \%$ spandex). Chemithermomechanical pulp fiber produced from hightemperature processes (HTCTMP) was provided by SCA (Östrand, Sweden). The size distribution of pulp was as follows: $49 \%$ of $3-7.5 \mathrm{~mm}, 14 \%$ of $2-3 \mathrm{~mm}, 14 \%$ of $1-2 \mathrm{~mm}$,
$9 \%$ of $0.5-1 \mathrm{~mm}$, and $14 \%$ of $0.2-0.5 \mathrm{~mm}$. Sodium dodecyl sulfate $(\geq 99.0 \%$ ), sulfonated kraft lignin (average $\mathrm{Mw}$ $\sim 10,000,4 \%$ sulfur, $\mathrm{pH} 10.5$, soluble in water, particle size $125-180 \mu \mathrm{m}$ ), and kraft lignin ( $5 \%$ moisture, pH 6.5, solubility in $\mathrm{NaOH}$ is $0.05 \%$, insoluble in water) were purchased from Sigma-Aldrich (Stockholm, Sweden). The two types of kraft lignin were produced by a hot alkaline (sulfate) process, and the sulfonated kraft lignin was modified by sulfonation. Nanoclay montmorillonite (Cloisite $\mathrm{Na}+$, the average thickness of individual platelets is $1 \mathrm{~nm}$, with $10-1000 \mathrm{~nm}$ dimensions, and a density of $2.86 \mathrm{~g} / \mathrm{cm}^{3}$ ) was provided by BYK Additives (Germany). Microfibrillated cellulose (MFC; $2 \%$ ) was provided by a local company. Commercial fire retardant-expandable graphite was provided by GrafTech (USA), and a commercial synergetic fire retardant (50\% ammonium sulfate, $10 \%$ ammonium polyphosphate, and $40 \%$ aluminum hydroxide) were obtained from a local company.

\section{Methods}

\section{Preparation of thermal insulating materials}

Cellulosic thermal insulating materials were produced using a foam-forming technique (Zheng et al. 2017a, Zheng et al. 2017b). Briefly, $23 \mathrm{~g}$ of HTCTMP and $23 \mathrm{~g}$ of recycled textile fibers were mixed with $1.3 \mathrm{~g}$ of sodium dodecyl sulfate surfactant in $1 \mathrm{~L}$ of water. The mixtures were mechanically stirred (3000 rpm, $15 \mathrm{~min}$ ) in an L\&W Pulp Disintegrator (ABB, Zürich, Switzerland) to produce foams, which were then dried $\left(90^{\circ} \mathrm{C}, 8 \mathrm{~h}\right.$ ) in a TS8000 oven (TERMAKS, Bergen, Norway).

\section{Coating on thermal insulating materials}

The MFC suspension concentration was diluted to $1 \%$ and homogenized using a T25 Ultra Turrax mixer (IKA, Staufen im Breisgau, Germany) at 10,000 rpm for $10 \mathrm{~min}$. The coating formulas are shown in Table 1 . The coating weight on each surface was $0.8 \mathrm{~kg} / \mathrm{m}^{2}$ and was quantified using an XA 204 balance (Mettler-Toledo, Greifensee, Switzerland). The coating process is depicted in Figure 1. The coated samples were dried at $80^{\circ} \mathrm{C}$ for $3 \mathrm{~h}$. The reference material was prepared without any coating.

\section{Density and coating weight gain percent}

The density of the insulating materials was calculated by dividing the weight determined using an XA 204 balance 


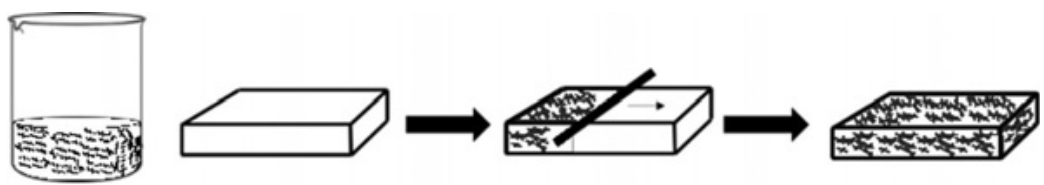

Figure 1: Coating process.

Table 1: Coating composition.

\begin{tabular}{ll}
\hline Sample & Coating composition \\
\hline Reference & No coating \\
MFC & $100 \%$ of MFC \\
Sulfonated kraft lignin + MFC & $\begin{array}{l}10 \% \text { of sulfonated kraft lignin and } \\
90 \% \text { of MFC }\end{array}$ \\
Kraft lignin + MFC & $10 \%$ of kraft lignin and $90 \%$ of MFC \\
Nanoclay + MFC & $10 \%$ of nanoclay and $90 \%$ of MFC \\
Synergetic fire retardant + MFC & $10 \%$ of synergetic fire retardant \\
& and $90 \%$ of MFC \\
Expandable graphite + MFC & $10 \%$ of expandable graphite and \\
& $90 \%$ of MFC \\
\hline
\end{tabular}

(Mettler-Toledo, Greifensee, Switzerland) by the volume. The samples were conditioned at $23{ }^{\circ} \mathrm{C}$ and $50 \%$ relative humidity for $24 \mathrm{~h}$ prior to weighing. The coating weight gain percent was calculated by the equation below; $W_{0}$ and $W_{1}$ are the weights of materials before and after coating.

$$
\text { Weight gain }(\%)=\frac{W_{1}-W_{0}}{W_{0}} \times 100
$$

\section{Scanning electron microscopy (SEM)}

The surface morphologies of the uncoated reference and coated insulating materials were observed in a scanning electron microscope (Hitachi S-4800 FE-SEM, JEOL Ltd., Japan) after gold/palladium sputtering. The thickness of the fire-retardant coating was measured using SEM software.

\section{Thermogravimetric analysis (TGA)}

The required coatings films were prepared by casting the fire retardants-MFC on Petri dishes and subsequently drying them for 3 hours at $80^{\circ} \mathrm{C}$. The thermal stabilities of the uncoated reference and the coating films without fiber were evaluated in nitrogen, from 25 to $800^{\circ} \mathrm{C}$ at a heating rate of $10^{\circ} \mathrm{C} / \mathrm{min}$ using a TGA/SDTA 851e (Mettler Toledo, Greifensee, Zürich, Switzerland). The samples (approximately $5 \mathrm{mg}$ ) were placed in alumina pans in a nitrogen atmosphere (gas flow, $50 \mathrm{~mL} / \mathrm{min}$ ). $\mathrm{T}_{\text {onset } 10 \% \text { (temperature }}$ at $10 \%$ of weight loss), $\mathrm{T}_{\max }$ (temperature at a maximum rate of weight loss), and the residue at $800{ }^{\circ} \mathrm{C}$ were measured.

\section{Ignition ability}

Single-flame source tests were carried out to evaluate the ignition ability of cellulosic thermal insulating materials. A single flame was applied to the surface or edge of the conditioned $\left(23^{\circ} \mathrm{C}, 50 \% \mathrm{RH}\right)$ samples $(250 \mathrm{~mm}$ long by $90 \mathrm{~mm}$ wide). Surface exposure was conducted when the flame was applied on the centerline of the sample surface, $40 \mathrm{~mm}$ above the bottom edge of the test sample. Edge exposure was carried out when the flame was applied to the center of the width of the bottom edge of the test sample, following standard EN ISO 11925-2 (CEN ISO 2010). The position reached by the flame after a 15-s flame application time and 20-s duration time was recorded. If the flame tip did not reach a $150-\mathrm{mm}$ limit, then the material was classified as class E according to standard EN 13501-1 (CEN 2007).

\section{Cone calorimetry}

The combustion of cellulosic thermal insulating materials (a length $\times$ width $\times$ thickness of $100 \times 100 \times 20 \mathrm{~mm}^{3}$ ) was measured by cone calorimetry (Fire Testing Technology, FTT, West Sussex, UK). The samples $(100 \mathrm{~mm} \times 100 \mathrm{~mm} \times$ $20 \mathrm{~mm}$ ) were subjected to a $25 \mathrm{~kW} / \mathrm{m}^{2}$ of radiant heat flux following the procedure described in standard ISO 5660-1 (ISO 2015). The time to ignition (TTI, s), peak heat release rate (Peak-HRR, $\mathrm{kW} / \mathrm{m}^{2}$ ), and total heat release (THR, $\mathrm{MJ} / \mathrm{m}^{2}$ ) were determined. Two repetitions of each sample were performed.

\section{Compressive strength}

Compressive strengths of cellulosic thermal insulating materials were measured using an Instron 5944 (Instron, High Wycombe, UK) instrument with a compression rate of $10 \%$ of the original sample thickness per min. The final strain 
Table 2: Density and weight gain percentage of the uncoated reference and coated thermal insulating materials.

\begin{tabular}{lrrr}
\hline Sample & Density before coating $\left(\mathbf{k g} / \mathbf{m}^{\mathbf{3}}\right)$ & Density after coating $\left(\mathbf{k g} / \mathbf{m}^{\mathbf{3}}\right)$ & Weight \\
\hline Reference & $34 \pm 2$ & - & - \\
MFC & $33 \pm 0$ & $43 \pm 0$ & 0 \\
Sulfonated kraft lignin + MFC & $35 \pm 1$ & $39 \pm 1$ & $20 \pm 0$ \\
Kraft lignin + MFC & $33 \pm 2$ & $40 \pm 1$ & $19 \pm 0$ \\
Nanoclay + MFC & $35 \pm 1$ & $39 \pm 0$ & $17 \pm 0$ \\
Synergetic fire retardant + MFC & $32 \pm 0$ & $39 \pm 0$ & $20 \pm 2$ \\
Expandable graphite + MFC & $33 \pm 0$ & $18 \pm 1$ \\
\hline
\end{tabular}

was $85 \%$ of the original sample height. Samples with a cross-sectional area of $25 \times 25 \mathrm{~mm}$ and a thickness of $20 \mathrm{~mm}$ were tested at a strain rate of $2 \mathrm{~mm} / \mathrm{min}$. All samples were conditioned at $23 \pm 1^{\circ} \mathrm{C}$ and $50 \% \mathrm{RH}$ for $48 \mathrm{~h}$ prior to the test. The data were recorded and averaged from 3 measurements.

\section{Thermal conductivity}

The thermal conductivity was determined with a Hot Disk TPS $2500 \mathrm{~S}$ instrument (Hot Disk AB, Göteborg, Sweden) using a $20 \mathrm{~mW}$ output power and a $40 \mathrm{~s}$ measurement time in isotropic mode. A 6.4-mm Ni wire sensor was used, and the samples were probed in bulk mode to obtain values for the thermal conductivity at $23^{\circ} \mathrm{C}$. All samples were conditioned for $24 \mathrm{~h}$ at $23^{\circ} \mathrm{C}$ and $50 \% \mathrm{RH}$. The data were averages from 3 replicates.

\section{Results and discussion}

\section{Density}

Table 2 shows the weight gain percentage of the coated insulating materials when MFC or fire retardants + MFC were coated on the thermal insulating materials. After coating, the weight increased by approximately $20 \%$ for most of the samples except the nanoclay-coated sample. This could be due to a loss of high-viscosity nanoclay particles + MFC coating. No obvious density increase was observed when $1 \%$ MFC was coated on the sample due to the limited dry mass of MFC. Additionally, the fire retardants + MFCcoated samples showed $20 \%$ increased weight.

\section{Scanning electron microscopy (SEM)}

As shown in Figure 2, the coated surfaces had different microscopic structures. For example, $0.8 \mathrm{~kg} / \mathrm{m}^{2}$ of MFC coat- ing did not cover the entire surface (Figure 2b) because the concentration of MFC suspension (1\%) was too low to cover the entire surfaces. Sulfonated kraft lignin + MFC coating (Figure 2c) resulted in a smoother sample compared with the other additives mixed with MFC. This could be due to a good film-forming ability of sulfonated kraft lignin in MFC, i. e., sulfonated kraft lignin readily dissolves in water and is well-compatible with MFC suspension due to the presence of the sulfonic group, leading to an improved surface activity (Ouyang et al. 2009).

The kraft lignin + MFC-coated samples (Figure 2d) showed a relatively rough surface; a few particles remained undissolved in the MFC solution. Nanoclay + MFC coating (Figure 2e) covered most of the surfaces and filled the voids between fibers, which may be related to the better dispersion of smaller particle size of nanoclay (10-1000 nm) in MFC. For the synergetic fire retardant + MFC and expandable graphite + MFC-coated samples, aluminum hydroxide particles (Figure 2f) and expandable graphite flakes (Figure 2g) were observed on the surfaces. The thickness of the MFC and nanoclay + MFC coating films were $0.02 \mathrm{~mm}$ and $0.03 \mathrm{~mm}$, respectively, and the thicknesses of other fire retardants + MFC coatings were approximately $0.2-0.3 \mathrm{~mm}$ as measured by SEM software. MFC and nanoclay + MFC created a 10-times thinner film than other fire retardants + MFC because of the smaller particle sizes of MFC and nanoclay.

\section{Thermogravimetric analysis (TGA)}

TGA was used to explore the thermal degradation behaviors, thermal stability, and final char formation of the uncoated reference and coating films. The curves and data are presented in Figure 3 and Table 3.

$\mathrm{T}_{\text {onset } 10 \%}$ denotes the initial decomposition temperature at which $10 \%$ material loss was reached. Nanoclay + MFC film had the highest onset decomposition temperature and final residue content $(87 \%)$ at $800^{\circ} \mathrm{C}$. The reference had the lowest residue yield due to a lower ther- 

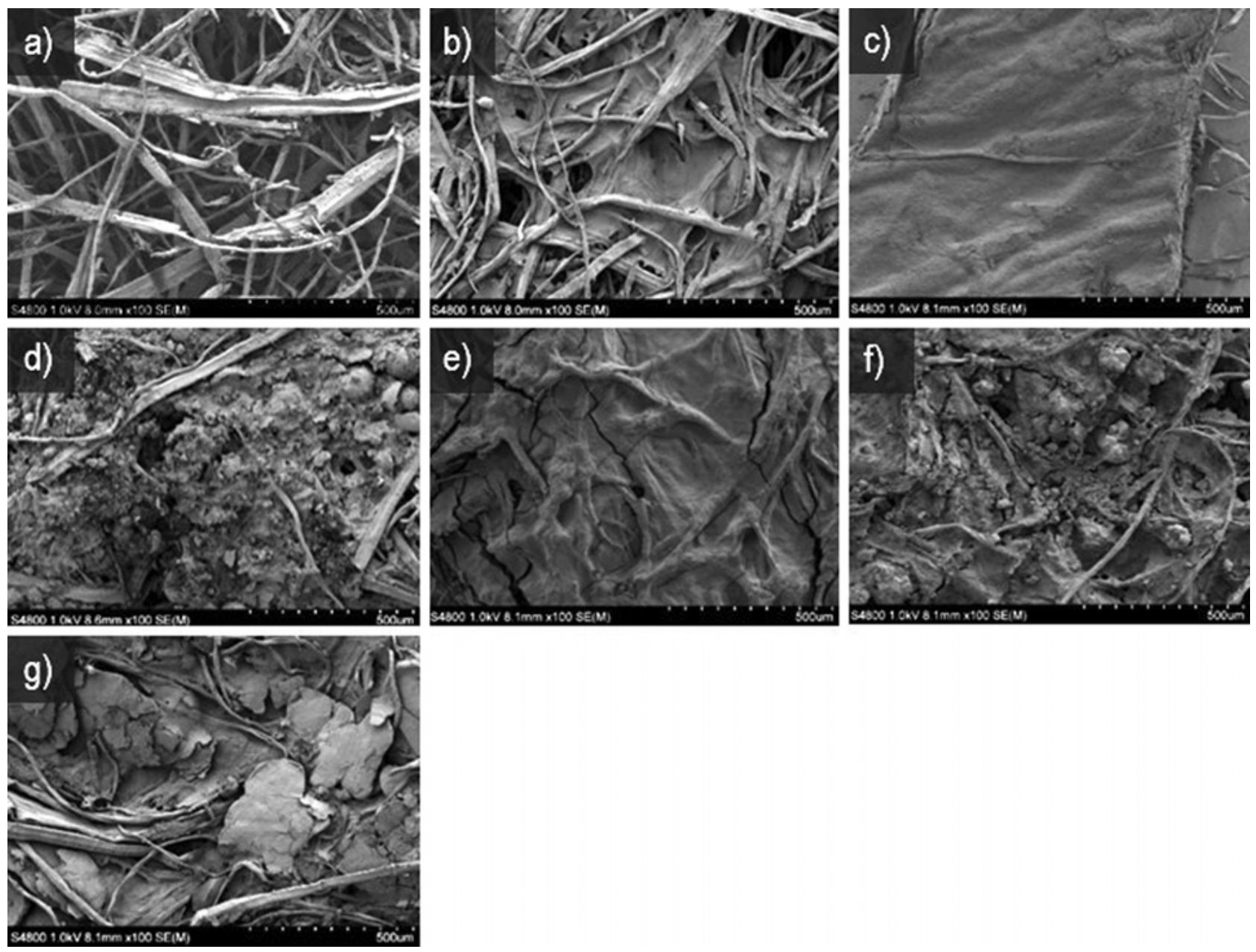

Figure 2: SEM images of the uncoated surfaces of reference and coated thermal insulating materials. (a) Reference; (b) MFC; (c) sulfonated kraft lignin + MFC; (d) kraft lignin + MFC; (e) nanoclay + MFC; (f) synergetic fire retardant + MFC; (g) expandable graphite + MFC.

mal stability of fibers consisting of $50 \%$ recycled cotton denim and $50 \%$ mechanical pulp fiber. Approximately $6 \%$ of synthetic fibers (polyurethane and spandex) in the denim fibers increased volatile yields and decreased final char yields. MFC film showed a slightly higher content of residue than the reference, which could be due to its higher purity and quantity of crystalline cellulose (Moriana et al. 2016). Sulfonated kraft lignin + MFC coating film had a lower onset temperature and an increased residue yield than kraft lignin + MFC, which could be due to a relatively higher sulfur content (4-5\%) from sulfonation or the kraft pulping process in sulfonated kraft lignin; kraft lignin only contains 2-3\% sulfur (Han, Sophonrat et al. 2018). The higher sulfur content and introduction of sulfonate groups $\left(\mathrm{SO}_{3}^{-}\right)$in the sulfonated kraft lignin catalyzes the dehydration of lignin, thus promoting the generation of esters and rearrangement and formation of condensed lignin structure. This results in a fabric more thermally stable than the unmodified kraft lignin (Ouyang et al. 2009, Konduri and Fatehi 2015, Prieur et al. 2016, Han et al. 2018).

Compared with the commercially synergetic fire retardant + MFC and expandable graphite + MFC coating films, the nanoclay montmorillonite + MFC coating was the most thermally stable sample during the overall thermal degradation process. The only volatile detected during the thermal degradation of nanoclay was water at $300^{\circ} \mathrm{C}$ (Cervantes-Uc et al. 2007). This indicated nanoclay can act as a good thermal insulator and a protective layer for cellulosic thermal insulating materials. $\mathrm{T}_{\max }$ represents the temperature at which the rate of weight loss reaches a maximum in the derivative curves due to rapid volatilization and carbonaceous residue formation (Kopczyński et al. 2015). The derivative curves of sulfonated kraft lignin + MFC, nanoclay + MFC, synergetic fire retardant $+\mathrm{MFC}$, and expandable graphite + MFC coating films showed multiple peaks (Figure $3 \mathrm{~b}$ ). This confirmed that more than two different thermal degradation events occurred. Compared 

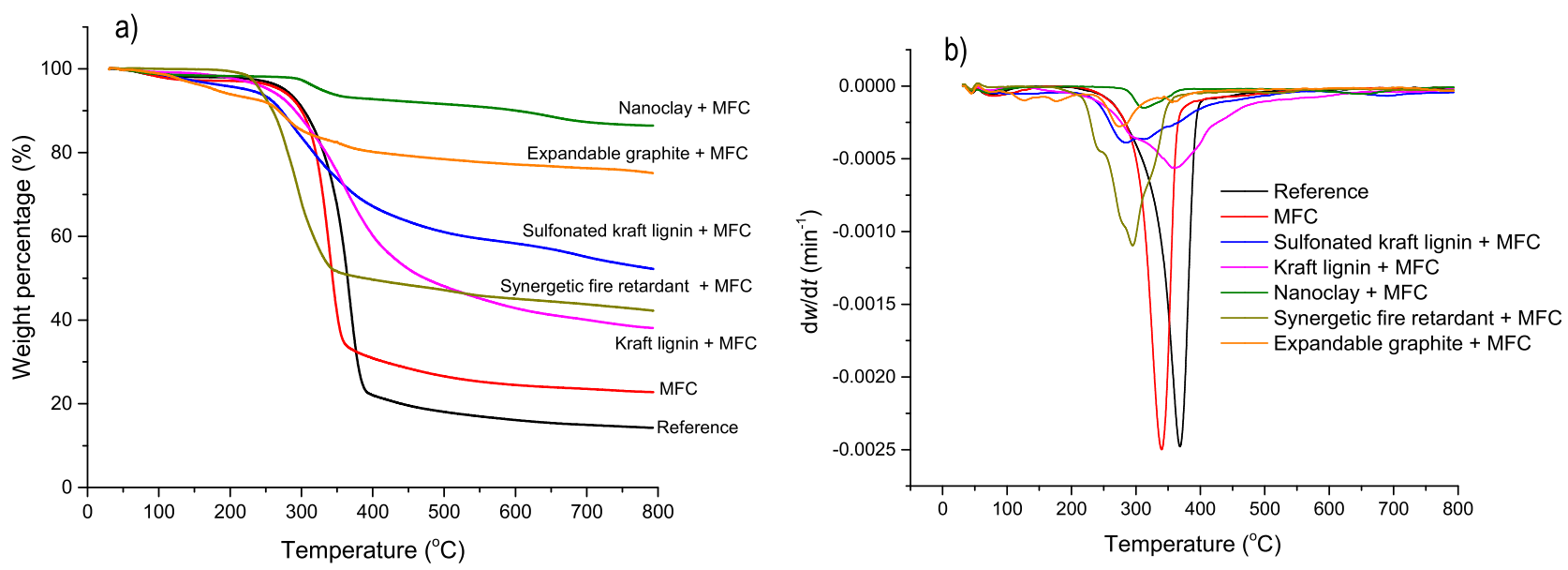

Figure 3: (a) TG and (b) DTG curves for the uncoated reference, MFC coating film, and fire retardants + MFC coating films.

Table 3: Thermalgravimetric analysis data of the uncoated reference and coating films.

\begin{tabular}{|c|c|c|c|c|c|}
\hline Sample & $\mathrm{T}_{\text {onset } 10 \%}\left({ }^{\circ} \mathrm{C}\right)$ & $\mathrm{T}_{\max 1}\left({ }^{\circ} \mathrm{C}\right)$ & $\mathrm{T}_{\max 2}\left({ }^{\circ} \mathrm{C}\right)$ & $\mathrm{T}_{\max 3}\left({ }^{\circ} \mathrm{C}\right)$ & Residue at $800^{\circ} \mathrm{C}(\%)$ \\
\hline Reference & $306 \pm 3$ & $367 \pm 1$ & - & - & $15 \pm 1$ \\
\hline MFC & $299 \pm 1$ & $343 \pm 3$ & - & - & $22 \pm 1$ \\
\hline Sulfonated kraft lignin + MFC & $270 \pm 1$ & $284 \pm 0$ & $690 \pm 0$ & - & $52 \pm 0$ \\
\hline Kraft lignin + MFC & $295 \pm 6$ & $356 \pm 0$ & - & - & $40 \pm 2$ \\
\hline Nanoclay + MFC & $617 \pm 19$ & $313 \pm 1$ & $651 \pm 10$ & - & $87 \pm 0$ \\
\hline Synergetic fire retardant + MFC & $263 \pm 3$ & $245 \pm 3$ & $297 \pm 2$ & - & $45 \pm 3$ \\
\hline Expandable graphite + MFC & $265 \pm 6$ & $128 \pm 1$ & $176 \pm 1$ & $272 \pm 4$ & $74 \pm 2$ \\
\hline
\end{tabular}

with the reference without any coatings, similar trends (i. e., decreasing $\mathrm{T}_{\max 1}$ and increasing char yield) were observed with the fire-retardant coatings as a result of the decomposition and dehydration of fire retardants and the generation of char. This resulted in a shift of the maximum weight loss temperature $\left(\mathrm{T}_{\max 2}\right)$ to a higher temperature in the late stage. Similar results have been reported for different types of fire retardant lignocellulosic materials (Altun et al. 2016, Zheng et al. 2017a, Mandlekar et al. 2018).

\section{Ignition ability}

The standard single-flame source test was used to determinate the ignition ability of the uncoated reference and coated cellulosic thermal insulating materials (CEN ISO 2010). The results showed that sulfonated kraft lignin + MFC, nanoclay + MFC, and two types of commercial fire retardants + MFC-coated samples met fire class $\mathrm{E}$ requirements in surface and edge exposure tests (Figure 4 and Figure 5). This indicated that the products can resist a small flame attack without substantial flame spread for short durations (CEN 2007). The burned areas on the surfaces of the sulfonated kraft lignin + MFC and nanoclay + MFC- coated samples were similar to those of the two types of commercial fire retardants (synergetic fire retardant and expandable graphite) + MFC-coated samples. These commercial fire retardants + MFC coatings performed much better compared with the same quantity of fire retardants added to fiber suspensions in foaming processes (Zheng et al. 2017a). These coatings can provide more efficient fire protection and thermal insulation effects, resulting in the generation of effective char layers on the surfaces of insulating materials (Weil 2011). However, the reference and MFC-coated samples did not pass the fire test and were completely burned (Figure 4a,b and Figure 5a,b). Additionally, the kraft lignin-coated samples also failed to pass the fire tests (Figure 4d and Figure 5d) likely due to a low formation of protective char residue and large release of flammable volatiles during the thermal degradation of unmodified kraft lignin. These results were confirmed by TGA (Table 3).

\section{Cone calorimetry}

Using a standard cone calorimetry test, the burning properties of the uncoated reference and coated samples were 


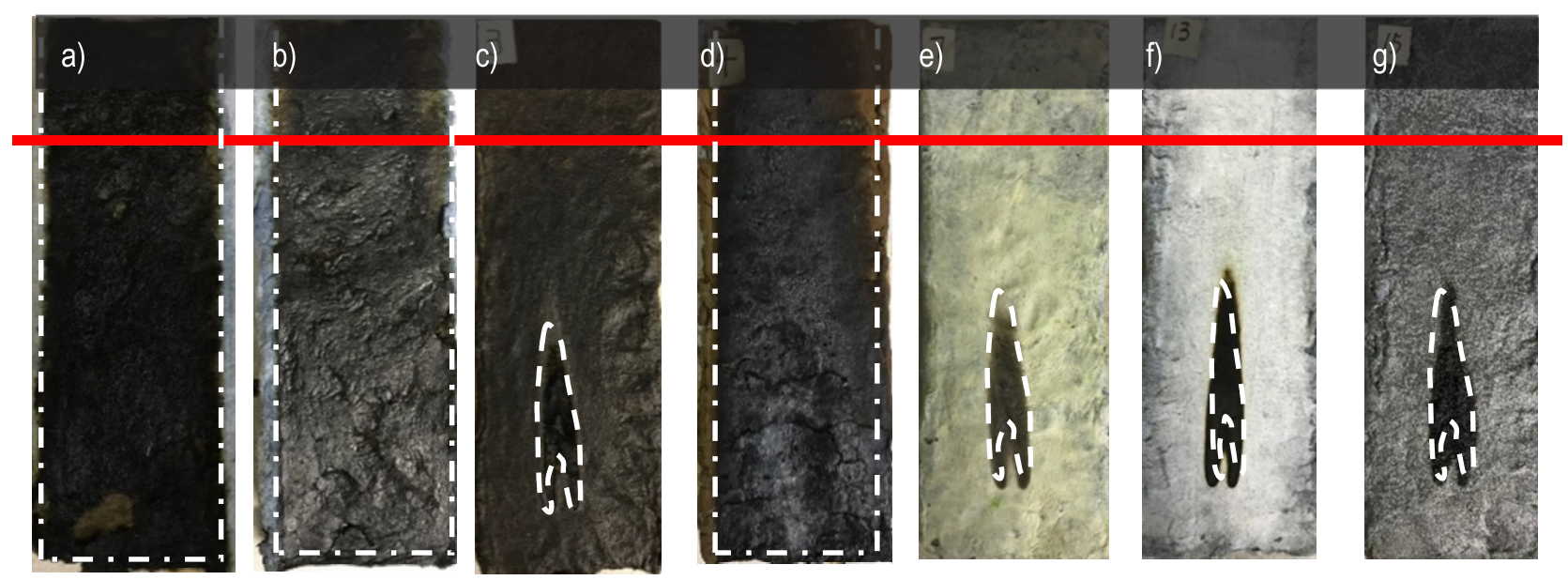

Figure 4: Single-flame source test (surface) results. (a) Reference; (b) MFC; (c) sulfonated kraft lignin + MFC; (d) kraft lignin + MFC; (e) nanoclay + MFC; (f) synergetic fire retardant + MFC; (g) expandable graphite + MFC. Note: burned areas are highlighted by dotted lines.

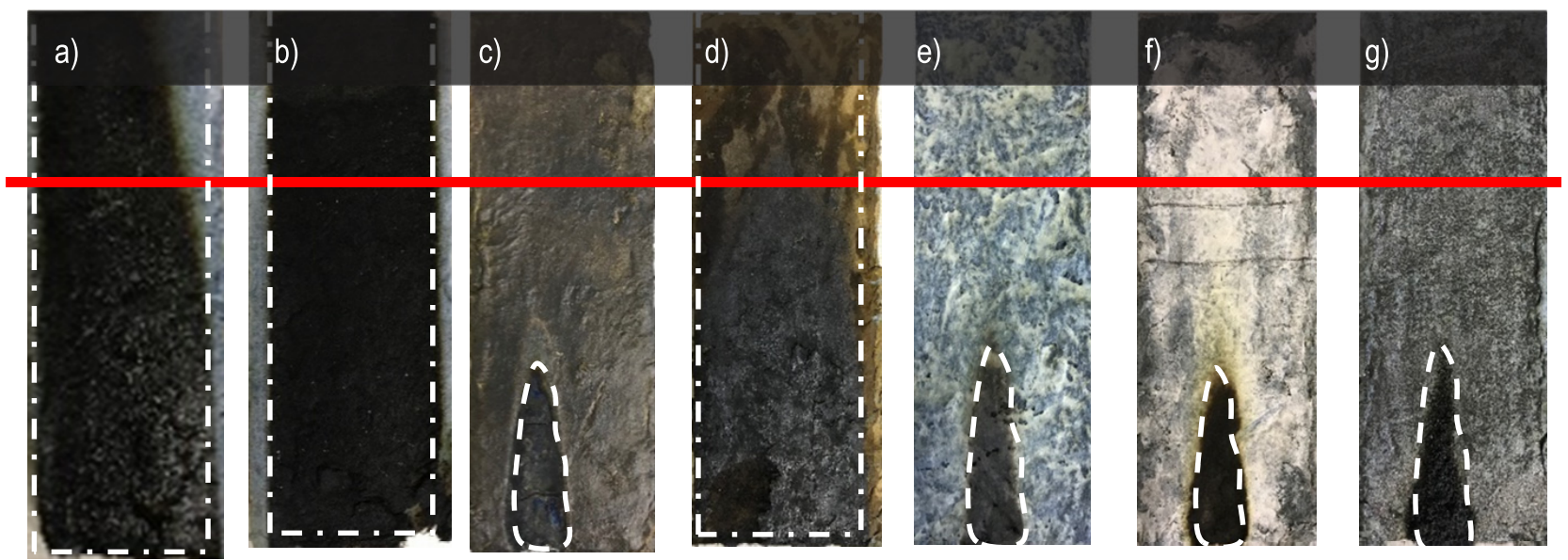

Figure 5: Single-flame source test (edge) results. (a) Reference; (b) MFC; (c) sulfonated kraft lignin + MFC; (d) kraft lignin + MFC; (e) nanoclay + MFC; (f) synergetic fire retardant + MFC; (g) expandable graphite + MFC. Note: burned areas are highlighted by dotted lines.

measured at a heat flux of $25 \mathrm{~kW} / \mathrm{m}^{2}$, which simulates a heat flux below vertical spreading wall flames in typical fires (ISO 2012). The results, e. g., times to ignition and heat release rates, are shown in Figure 6 and Table 4.

The peak heat release rate of the sulfonated kraft lignin + MFC-coated sample decreased by $30 \%$ (Figure 6 ) compared with the uncoated reference. A lower peak heat release rate indicates a reduced flammability and a decreased amount of oxygen consumed in a fire (Brohez 2005). Compared with the uncoated reference and other coated samples, the nanoclay + MFC-coated sample did not ignite under a heat flux of $25 \mathrm{~kW} / \mathrm{m}^{2}$. This sample performed the best due to the generation of the most efficient char layer and a very limited production of flammable volatiles during nanoclay thermal decomposition. The improved fire retardancy resulted from the formation of a protective char layer during the degradation of the surface coating. This char layer prevented the underlying substrate from further decomposing by reducing heat transfer and flammable volatile release, thereby decreasing heat release rates and improving fire retardancy (Marney et al. 2008, Laoutid et al.2009). The results were consistent with the SEM, TGA, and single-flame source test results (Figure 2e, Figure 3, Figure 4e, and Figure 5e). As shown in Figure $7 \mathrm{e}$ and Figure $8 \mathrm{e}$, the residues after cone calorimetry test and the SEM images showed that the nanoclay + MFCcoated sample had a compact and intact char layer on the surface, and the underlying cellulosic insulating materials were protected from thermal decomposition.

The expandable graphite + MFC-coated samples had a similar peak heat release rate compared with that for the same quantity of fire retardant added to the fiber sus- 
Table 4: Cone calorimetry results for the uncoated reference and coated thermal insulating materials.

\begin{tabular}{lrrr}
\hline Sample & TTI (s) & Peak HRR $\left(\mathbf{k W} / \mathbf{m}^{\mathbf{2}}\right)$ & THR $\left(\mathbf{M} \mathbf{3} \mathbf{m}^{\mathbf{2}}\right)$ \\
\hline Reference & $12 \pm 4$ & $120.0 \pm 5.8$ & $9.5 \pm 0.7$ \\
MFC & $18 \pm 1$ & $126.6 \pm 9$ & $10.8 \pm 1.1$ \\
Sulfonated kraft lignin + MFC & $12 \pm 1$ & $84.9 \pm 3.9$ & $8.4 \pm 2.0$ \\
Kraft lignin + MFC & $14 \pm 2$ & $126.6 \pm 8.0$ & $11.1 \pm 0.8$ \\
Nanoclay + MFC & No Ignition & $5.4 \pm 0.8$ & $0.4 \pm 0.1$ \\
Synergetic fire retardant + MFC & $34 \pm 2$ & $47.2 \pm 5.6$ & $4.2 \pm 0.2$ \\
Expandable graphite + MFC & $26 \pm 8$ & $47.0 \pm 0.5$ & $7.0 \pm 0.4$ \\
\hline
\end{tabular}

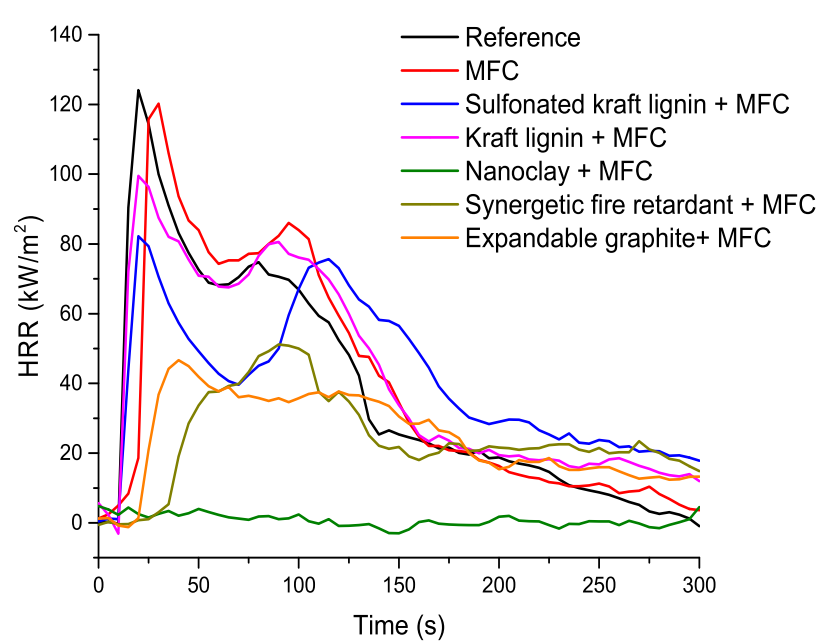

Figure 6: Heat release rate (HRR) curves for the uncoated reference, MFC and fire retardants coated thermal insulating materials.

pension in the foaming process. However, the expandable graphite + MFC-coated sample had a 3-times longer time to ignition (Zheng et al.2017a). This was due to the expansion of the expandable graphite into a worm-like char layer (Figure $8 \mathrm{~g}$ ) at $160-170^{\circ} \mathrm{C}$ caused by redox reactions between $\mathrm{H}_{2} \mathrm{SO}_{4}$ and the layered graphite (Camino et al. 2001). The efficient intumescent effect of expanded graphite created a 3-mm thick char layer on the surface and thus, delayed the time to ignition (Figure 7g).

For the synergetic fire retardant + MFC-coated sample, the residue formed a shrunken char and could not maintain its original shape. This was due to stress changes during the catalytic dehydration of cellulosic fibers by polyphosphates produced during ammonium polyphosphate (APP) decomposition (Seefeldt et al. 2012), water release and formation of $\mathrm{Al}_{2} \mathrm{O}_{3}$ (Figure 8f) from aluminum hydroxide (ATH) decomposition at $180^{\circ} \mathrm{C}$ (Musbah Redwan et al. 2015), and the evolution of diluted gases, such as $\mathrm{NH}_{3}$ (Statheropoulos and Kyriakou 2000). Additionally, the generation of thermally stable char resulted in a higher $\mathrm{T}_{\max }$ in the late stage, as evidenced by thermal gravimet-
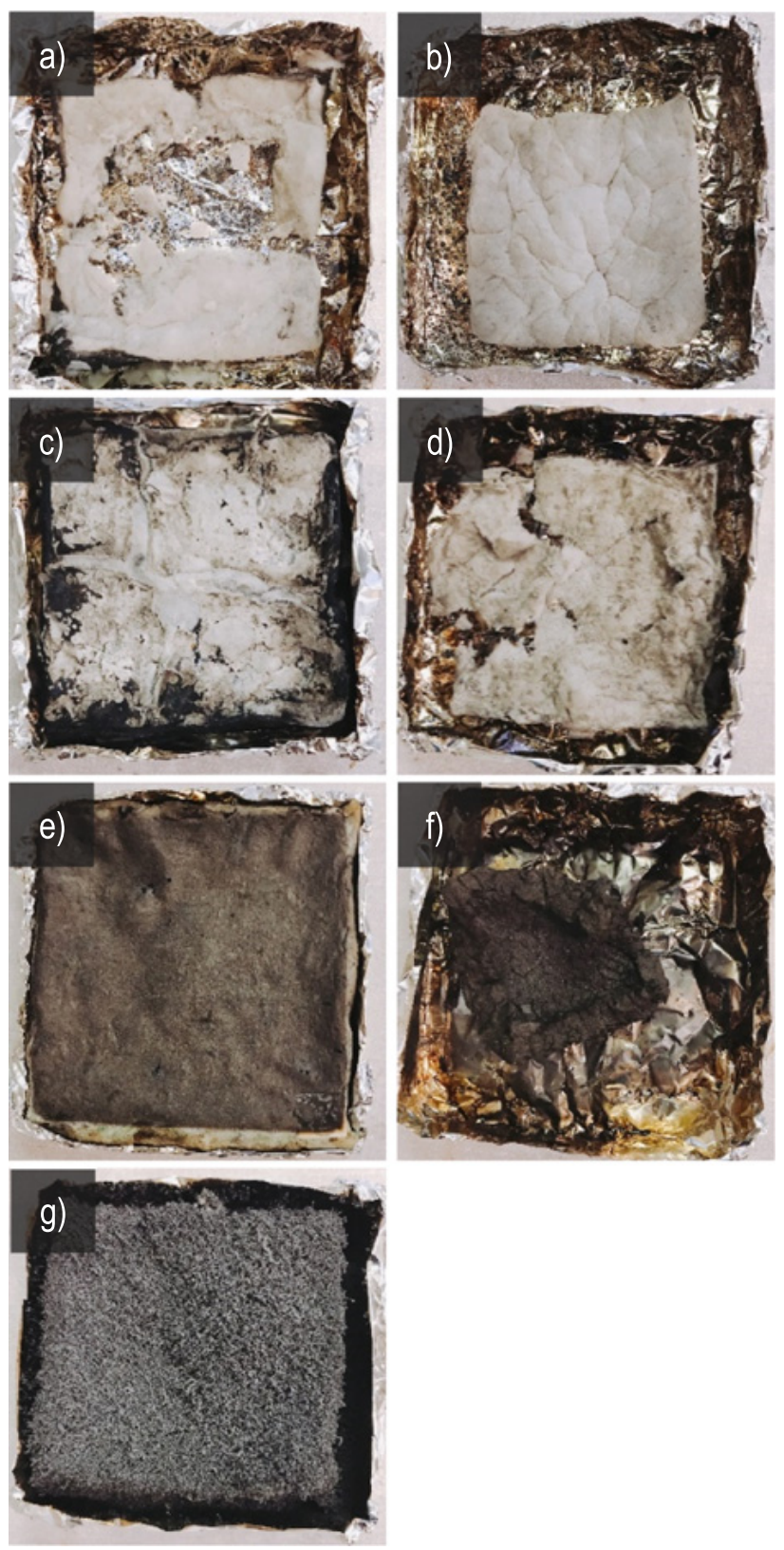

Figure 7: Residues after cone calorimetry test. (a) Reference; (b) MFC; (c) sulfonated kraft lignin + MFC; (d) kraft lignin + MFC; (e) nanoclay + MFC; (f) synergetic fire retardant + MFC; (g) expandable graphite + MFC. 

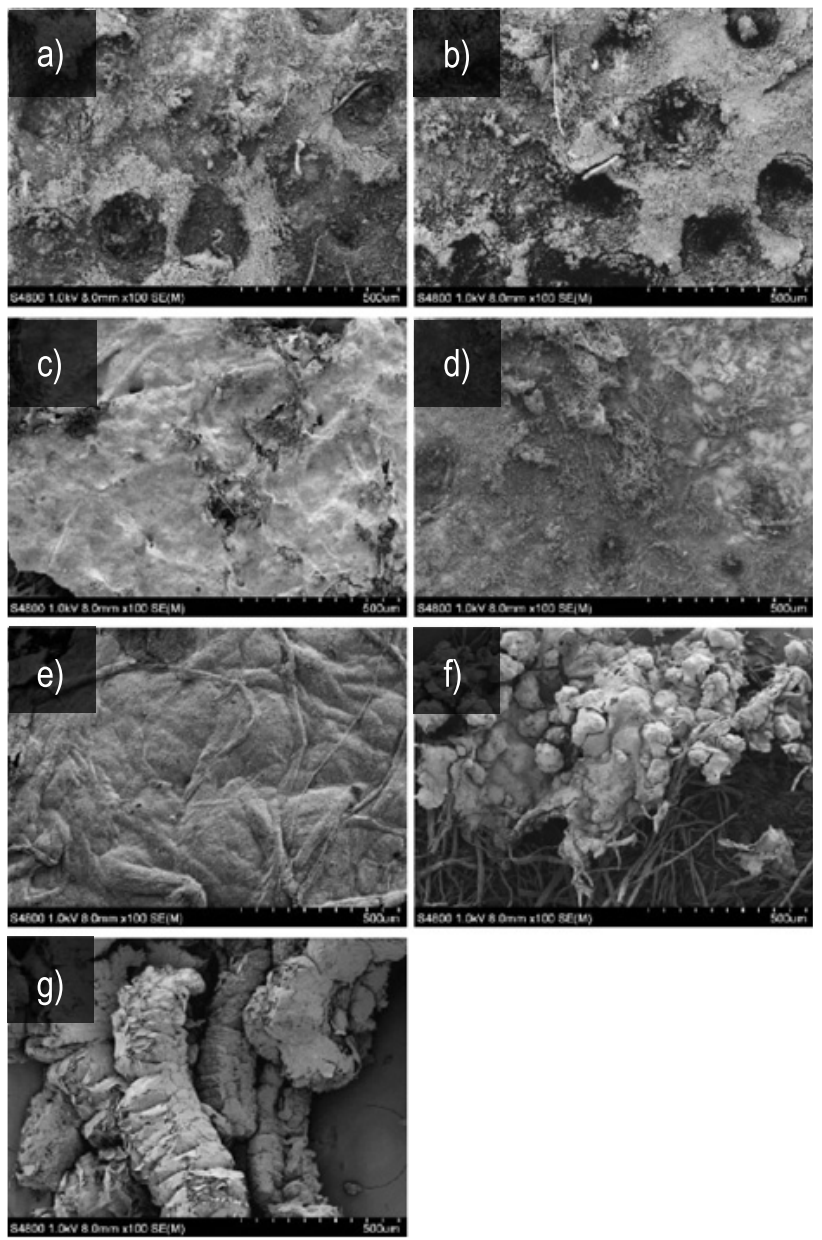

Figure 8: SEM images of samples after the cone calorimetry test. (a) Reference; (b) MFC; (c) sulfonated kraft lignin + MFC; (d) kraft lignin + MFC; (e) nanoclay + MFC; (f) synergetic fire retardant + MFC; (g) expandable graphite + MFC.

ric analysis (Figure 3). For the uncoated reference, MFC, and kraft lignin + MFC-coated samples, only loose residues and no char layer were observed (Figure 7a,b,d and Figure $8 \mathrm{a}, \mathrm{b}, \mathrm{d})$. These results agreed with the results of the single-flame source tests. Samples with a peak heat release rate greater than $120 \mathrm{~kW} / \mathrm{m}^{2}$ did not pass the single flame source test. A large amount of oxygen was consumed when flammable volatiles were released. The thermal insulating materials reacted with fire when the surface broke up, leading to the second peak heat release rate in Figure 6 and increased flammability (Zheng et al. 2017a).

\section{Thermal conductivity}

The thermal conductivity values of samples before and after coating are shown in Table 5. Generally, in warm climates, thermal insulation can reduce the indoor temper-
Table 5: Thermal conductivity of the uncoated reference and coated thermal insulating materials.

\begin{tabular}{lr}
\hline Sample & Thermal conductivity $(\mathrm{W} / \mathrm{m} / \mathrm{K})$ \\
\hline Reference & $0.041 \pm 0$ \\
MFC & $0.045 \pm 0.001$ \\
Sulfonated kraft lignin + MFC & $0.045 \pm 0$ \\
Kraft lignin + MFC & $0.043 \pm 0$ \\
Nanoclay + MFC & $0.045 \pm 0.001$ \\
Synergetic fire retardant + MFC & $0.045 \pm 0.001$ \\
Expandable graphite + MFC & $0.047 \pm 0.001$ \\
\hline
\end{tabular}

atures and cooling energy use in hot summer. Requirements are stricter in colder climates than in warmer climates, even though the standards differ significantly between countries and regions. Thermal conductivity is a very important parameter used to evaluate the thermal insulating properties (Gibson et al. 2012). A lower thermal conductivity indicates a better thermal insulation capacity (Pfundstein et al. 2008). Increased density resulted in increased thermal conductivity; this was due to increased solid conductivity induced by increased heat transfer through a high-density surface. The thermal conductivity of the coated samples $(0.045-0.047 \mathrm{~W} / \mathrm{m} / \mathrm{K}$, density $40 \mathrm{~kg} / \mathrm{m}^{3}$ ) was slightly lower than those of other pulpfiber-based thermal insulating materials $(0.048 \mathrm{~W} / \mathrm{m} / \mathrm{K}$, density $30 \mathrm{~kg} / \mathrm{m}^{3}$ ) (Zheng et al. 2017b). This was due to reduced radiative heat transfer and thermal convection due to increased densities and thus, result in a lower total thermal conductivity (Scheiding 2000, Simmler et al. 2005, Pöhler et al. 2017). The thermal conductivity values meet the requirements of thermal insulating materials in buildings. If the thermal conductivity of a material is lower than $0.07 \mathrm{~W} / \mathrm{m} / \mathrm{K}$, then this material can be considered a thermal insulating material (Dilmac and Kesen 2003).

\section{Compressive strength}

The compressive strength values of the uncoated reference sample and coated samples are presented in Table 6 . The coated samples had higher compressive strengths (increased by $30 \%$ to $170 \%$ ) than the uncoated reference sample. The coated samples had 3-4 times higher compressive strengths compared with similar cellulosic thermal insulating materials $(0.025-0.049 \mathrm{MPa}$, density $25-32 \mathrm{~kg} / \mathrm{m}^{3}$ ) reported in previous works (Zheng et al. 2017b). The coatings may fill the spaces between fibers and result in reinforcement effects, leading to increased compressive strengths of the coated cellulosic thermal insu- 
Table 6: Compressive strength of the uncoated reference and coated thermal insulating materials.

\begin{tabular}{lr}
\hline Sample & Compressive strength $(\mathrm{MPa})$ \\
\hline Reference & $0.069 \pm 0.005$ \\
MFC & $0.103 \pm 0.043$ \\
Sulfonated kraft lignin + MFC & $0.143 \pm 0.053$ \\
Kraft lignin + MFC & $0.190 \pm 0.016$ \\
Nanoclay + MFC & $0.096 \pm 0.017$ \\
Synergetic fire retardant + MFC & $0.081 \pm 0.015$ \\
Expandable graphite + MFC & $0.091 \pm 0.024$ \\
\hline
\end{tabular}

lating materials. The compressive strengths of the porous thermal insulating materials depended on their macroporosity, macropore sizes and geometry, and the strengths of the supports. Decreased surface macroporosity may induce the generation of struts from the coating that could increase the compressive strength. Similar results have been reported by Miao et al. (Miao et al. 2008).

\section{Conclusion}

Cellulosic thermal insulating materials were produced from recycled denim and mechanical pulp fibers using the foam-forming technique. Different types of bio-based fire retardants (sulfonated kraft lignin, kraft lignin, and nanoclay) and commercial fire retardants were combined with microfibrillated cellulose (MFC) binder to improve the thermal coating formulations. These formulations were coated on the cellulosic thermal insulating materials to improve their fire retardancy.

The effects of the coatings on reaction-to-fire properties, microscopic surfaces, thermal insulating performances, and mechanical properties of the thermal insulating materials were studied. Sulfonated kraft lignin + MFC and nanoclay + MFC coatings improved the fire retardancy of cellulosic thermal insulating materials and the coated samples met the requirements of fire class $\mathrm{E}$ according to single-flame source test results. This indicated that these products can resist a small flame attack without substantial flame spread for a short period of time. Sulfonation of kraft lignin promoted the generation of protective char layers, leading to greater fire retardancy compared with unmodified kraft lignin. The nanoclay + MFC-coated materials performed the best among the bio-based fiber retardants, i. e., no ignition was observed under a heat flux of $25 \mathrm{~kW} / \mathrm{m}^{2}$. Furthermore, the compressive strengths of the fire retardants + MFC-coated cellulosic thermal insulating materials significantly increased due to reinforcement ef- fects. The thermal insulating capacity of the coated samples indicates that the coating is a promising technique for improving the fire retardancy of thermal insulating materials. The coating technique combining green fire retardants, such as sulfonated kraft lignin and nanoclays, with MFC binder is a simple, affordable, and effective method for reducing the flammability of cellulosic thermal insulating materials.

Acknowledgments: SCA AB (Östrand, Sweden), BYK Additives (Germany), and GrafTech (USA) are thanked for providing the raw materials.

Funding: C. Zheng acknowledges the China Scholarship Council for offering financial support to this doctoral program. The Swedish Research Council Formas (Grant/ Award number: "2014-6986-29014-28”) is acknowledged for the financial support provided to the project: "Energyefficient cellulosic insulation products/panels for green building solutions."

Conflict of interest: The authors declare no conflicts of interest.

\section{References}

Altun, Y., Doğan, M., et al. (2016) The effect of red phosphorus on the fire properties of intumescent pine wood flour - LDPE composites. Fire Mater. 40(5):697-703.

Bertini, F., Canetti, M., et al. (2012) Effect of ligno-derivatives on thermal properties and degradation behavior of poly(3-hydroxybutyrate)-based biocomposites. Polym. Degrad. Stab. 97(10):1979-1987.

Brohez, S. (2005) Uncertainty analysis of heat release rate measurement from oxygen consumption calorimetry. Fire Mater. 29(6):383-394.

Camino, G., Duquesne, S., et al. (2001) Mechanism of expandable graphite fire retardant action in polyurethanes. In: Fire and Polymers, Eds. Nelson, G.L., Wilkie, C.A., American Chemical Society, Washington, DC. pp. 90-109.

Canetti, M., Bertini, F. (2007) Supermolecular structure and thermal properties of poly(ethylene terephthalate)/lignin composites. Compos. Sci. Technol. 67(15-16):3151-3157.

Canetti, M., Bertini, F., et al. (2006) Thermal degradation behaviour of isotactic polypropylene blended with lignin. Polym. Degrad. Stab. 91(3):494-498.

CEN (2007) Fire classification of construction products and building elements. Classification using test data from reaction to fire tests. Standard 13501-1 European Committee for Standardization, Brussels, Belgium.

CEN ISO (2010) Reaction to fire tests. Ignitability of products subjected to direct impingement of flame. Single-flame source test. Standard 11925-2 European Committee 
for Standardization and International Organization for Standardization, Belgium and Switzerland.

Cervantes-Uc, J.M., Cauich-Rodríguez, J.V., et al. (2007) Thermal degradation of commercially available organoclays studied by TGA-FTIR. Thermochim. Acta 457(1-2):92-102.

Chatterjee, S., Shanmuganathan, K., et al. (2017) Fire-retardant, self-extinguishing inorganic/polymer composite memory foams. ACS Appl. Mater. Interfaces 9(51):44864-44872.

Dilmac, S., Kesen, N. (2003) A comparison of new Turkish thermal insulation standard (TS 825), ISO 9164, EN 832 and German regulation. Energy Build. 35(2):161-174.

El-Darwish, I., Gomaa, M. (2017) Retrofitting strategy for building envelopes to achieve energy efficiency. Alex. Eng. J. 56(4):579-589.

Ferry, L., Dorez, G., et al. (2015) Chemical modification of lignin by phosphorus molecules to improve the fire behavior of polybutylene succinate. Polym. Degrad. Stab. 113:135-143.

Gibson, G., Ramsson, T., et al. (2012) Building shell and thermal insulation-technology brief R01. The Energy Technology Systems Analysis Program. https://iea-etsap.org.

Han, T., Sophonrat, N., et al. (2018) Evolution of sulfur during fast pyrolysis of sulfonated kraft lignin. J. Anal. Appl. Pyrolysis 133:162-168.

Hu, Y., Yu, B., et al. (2017) Novel fire-retardant coatings. In: Novel Fire Retardant Polymers and Composite Materials, Ed. Wang, D.-Y., Woodhead Publishing, Cambridge, UK. pp. 53-91.

ISO (2012) Reaction-to-fire tests heat release, smoke production and mass loss rate part 3: Guidance on measurement. Standard 5660-3 International Organization for Standardization, Switzerland.

ISO (2015) Standard 5660-1: Reaction-to-fire tests heat release, smoke production and mass loss rate part 1: Heat release rate (cone calorimeter method) and smoke production rate (dynamic measurement). International Organization for Standardization, Switzerland.

Konduri, M.K.R., Fatehi, P. (2015) Production of water-soluble hardwood kraft lignin via sulfomethylation using formaldehyde and sodium sulfite. ACS Sustain. Chem. Eng. 3(6):1172-1182.

Kopczyński, M., Plis, A., et al. (2015) Thermogravimetric and kinetic analysis of raw and torrefied biomass combustion. Chem. Eng. Prog. 36(2):209-223.

Lacoste, C., El Hage, R., et al. (2018) Sodium alginate adhesives as binders in wood fibers/textile waste fibers biocomposites for building insulation. Carbohydr. Polym. 184:1-8.

Laoutid, F., Bonnaud, L., et al. (2009) New prospects in flame retardant polymer materials: From fundamentals to nanocomposites. Mater. Sci. Eng., R Rep. 63(3):100-125.

Mandlekar, N., Malucelli, G., et al. (2018) Fire retardant action of zinc phosphinate and polyamide 11 blend containing lignin as a carbon source. Polym. Degrad. Stab. 153:63-74.

Marney, D., Russell, L., et al. (2008) The suitability of halloysite nanotubes as a fire retardant for nylon 6. Polym. Degrad. Stab. 93(10):1971-1978.

Miao, X., Tan, D.M., et al. (2008) Mechanical and biological properties of hydroxyapatite/tricalcium phosphate scaffolds coated with poly(lactic-co-glycolic acid). Acta Biomater. 4(3):638-645.
Moriana, R., Vilaplana, F., et al. (2016) Cellulose nanocrystals from forest residues as reinforcing agents for composites: A study from macro- to nano-dimensions. Carbohydr. Polym. 139:139-149.

Mousavioun, P., Doherty, W.O.S., et al. (2010) Thermal stability and miscibility of poly(hydroxybutyrate) and soda lignin blends. Ind. Crop. Prod. 32(3):656-661.

Musbah Redwan, A., Haji Badri, K., et al. (2015) The effect of aluminium hydroxide (ATH) on the mechanical properties and fire resistivity of palm-based fibreboard prepared by pre-polymerization method. Adv. Mater. Res. 1087:287-292.

Ouyang, X., Ke, L., et al. (2009) Sulfonation of alkali lignin and its potential use in dispersant for cement. J. Dispers. Sci. Technol. 30(1):1-6.

Pfundstein, M., Gellert, R., et al. Insulating Materials: Principles, Materials, Applications. Walter de Gruyter, Regensburg, Germany, 2008.

Prieur, B., Meub, M., et al. (2016) Phosphorylation of lignin to flame retard acrylonitrile butadiene styrene (ABS). Polym. Degrad. Stab. 127:32-43.

Pöhler, T., Jetsu, P., et al. (2017) Use of papermaking pulps in foam-formed thermal insulation materials. Nord. Pulp Pap. Res. J. 32(03):367-374.

Richmond, F. Cellulose Nanofibers Use in Coated Paper. The University of Maine, Orono, USA, 2014.

Scheiding, W. (2000) Thermal conductivity of wood fibers for insulation panels. Holz Roh- Werkst. 58(3):0177-0181.

Seefeldt, H., Braun, U., et al. (2012) Residue stabilization in the fire retardancy of wood-plastic composites: Combination of ammonium polyphosphate, expandable graphite, and red phosphorus. Macromol. Chem. Phys. 213(22):2370-2377.

Shan, G., Jin, W., et al. (2015) Flame-retardant polymer nanocomposites and their heat-release rates. J. Hazard. Toxic Radioact. Waste 19(4):04015006.

Simmler, H., Brunner, S., et al. (2005) Vacuum insulation panels-study on VIP-components and panels for service life prediction of VIP in building applications (subtask a). http://www.iea-ebc.org.

Song, P., Cao, Z., et al. (2011) Thermal degradation and flame retardancy properties of ABS/lignin: Effects of lignin content and reactive compatibilization. Thermochim. Acta 518(1-2):59-65.

Statheropoulos, M., Kyriakou, S. (2000) Quantitative thermogravimetric-mass spectrometric analysis for monitoring the effects of fire retardants on cellulose pyrolysis. Anal. Chim. Acta 409(1):203-214.

Weil, E.D. (2011) Fire-protective and flame-retardant coatings - a state-of-the-art review. J. Fire Sci. 29(3):259-296.

Yurddaskal, M., Celik, E. (2018) Effect of halogen-free nanoparticles on the mechanical, structural, thermal and flame retardant properties of polymer matrix composite. Compos. Struct. 183:381-388.

Zheng, C., Li, D., et al. (2017a) Cellulose-fiber-based insulation materials with improved reaction-to-fire properties. Nord. Pulp Pap. Res. J. 32(3):466-472.

Zheng, C., Li, D., et al. (2017b) Cellulose fiber based fungal and water resistant insulation materials. Holzforschung 71(7-8):633-639. 